\title{
Analysis on the Causes and Solutions of Teenagers' Excessive and Impulse Consumption
}

\begin{abstract}
Ruohan Qin ${ }^{1}$
${ }^{1}$ Yixing High School, Yixing, Jiangsu 214200, China

Corresponding author's e-mail: vivian.wang@cas-harbour.org

ABSTRACT

Impulse consumption refers to the unplanned and unconscious purchase behavior of customers under the impetus of external factors. At the same time, it will also cause excessive consumption to a certain extent, which is not compatible with national conditions and the level of economic development. Thus, understanding the importance of excessive and impulse consumption is necessary for teenagers. This article contains much of existing knowledge and discoveries about the subject, and these are studied. By now, the main causes are the inconsistency of consumption concepts and the lack of cognition and experience. Besides, the widespread use of mobile phones and different advertising have spurred this. Although excessive consumption can increase economic growth, it also causes these young people to have zero savings, negative savings, and even borrowing problems.General methods for reducing this problem have been proposed, including improvement of self-control among teenagers, procrastination, and moderate consumption.
\end{abstract}

Keywords: Behavioral economics, impulse consumption, excessive consumption, methods for reducing excessive consumption

\section{INTRODUCTION}

According to statistics from the Ministry of Commerce, the turnover of online retail in China on the day of "Double 11" in 2018 exceeded 300 billion yuan, among which the young consumer group accounted for over $70 \%$, becoming the main force of consumption [1]. However, the income of young people does not match the proportion of their consumption. In September 2019, CBNData and YOHO jointly released the white paper on The Development of China's Trend Consumption, which pointed out that "the post-90s, post-95s and post-00s generation are the main consumers in the online trend market, accounting for $80 \%$ of the consumption scale". In recent years, the per capital consumption expenditure of residents continues to rise, especially for teenagers. This may have contributed to GDP growth, but it is more of a problem. From the perspective of behavioral economics, this paper will focus on the analysis of the causes of this behavior and the stimulus factors, and discuss how to solve this problem. The hope is that it will help people resist impulse buying.

\subsection{Causes of Impulse Buying}

The hypothesis of rational man [2] is commonly used in economics. However, in reality, many people, especially young people, do not follow it in their behaviors. On the contrary, their behaviors are irrational in most cases, which has been proposed in behavioral economics [3], which combine analytical theory with psychology, laws of economic operation with economic science to find errors or omissions in current economic models. The reasons for their irrational decisions are discussed below.

Conformity or mind of rivalry. Conformity refers to that consumers do not buy certain goods out of material needs, but from the psychological gap formed by keeping up with the peers. When young people is not fully mature, they are more easily affected, for example, when friends bought a new mobile phone, brand clothes or cosmetics, peers might follow others' actions and choices, and will constantly look for ways to purchase, causing the impulse buying, and even if most of the them do not have enough ability to afford.

Self-consciousness and self-concept. The term "Self" originates from psychology. In 1890, William James, a psychologist at Harvard University, put forward 
self-consciousness and self-concept for the first time in his book Principles of Psychology [4]. Sirgy, M. J.believes that consumers tend to reinforce their selfconcepts by consuming items with personal symbolism[5]. For example, the purchase, display and use of goods by individuals can convey symbolic meaning, and the purchase and use of some products can also enhance consumers' self-esteem or make them better recognize their own "identity".

Addiction to consumption. Addictive goods consumption was originally used for tobacco, alcohol, heroin, etc., It is widely thought that people began to use drugs to get "pleasure". Although continuously using drugs could reduce this kind of pleasure, but in order to avoid the unpleasant feeling, people will have to continue to use. This hedonic attribute can be integrated into consumers' choice. Meanwhile, Becker and Murphy put forward the rational addiction theory [6], believing that the marginal utility of addictive items will increase with the addiction status. For example, some girls are very fond of buying cosmetics, while boys like to buy electronic products and running shoes.

Overconfidence leads to excessive consumption. Overconfidence refers to the tendency for people to overestimate their chances of success by placing too much trust in their own judgment. Licthenstein, Fischhoffand and Phillips [7] have conducted a series of studies on the psychological behavior of human decision making, in which participants were first asked some relevant questions and then were asked to estimate the probability of correct answers. The results found that people often overestimate their own judgments, for example, even when all the participants were sure their answers were correct, only 80 percent or less got them right. Nowadays, influenced by social networks, some young people have too much faith in their luck and ability to make money in the future, and has lower suffering consciousness. Therefore, they blindly make excessive consumption behavior, and believe that in the future they can fill their financial hole caused by consumption. According to economics, rational consumers will save part of their income to prevent the risk brought by uncertain factors in the future, while in real life, irrational people will reduce their savings rate or even zero savings or negative savings due to overconfidence, thus leading to insufficient savings and excessive consumption.

Diderot Effect. When people buy new items, other items will seem outdated and mismatched, motivating them to keep buying until all other items are all replaced. The concept was first documented in 1998 by Juliet B. Schor [8], an economist at Harvard University, in The Overspending American.

Emotional consumption. When filled with negative emotions such as dissatisfaction or grievance, some people will release their emotions by retaliatory purchases. However, experimental psychologist Dr. Ian
Zimmerman has found that the happiness generated by impulse spending fades quickly, followed by a great sense of loss, as you spend a lot of money [9]. Emotional consumption is mainly a means of regulating their own emotions.

\subsection{Stimuli of Impulse Buying}

The widespread use of smart phones. Research by $\mathrm{PhD}$ students at the University of Missouri suggests that being separated from our iPhones can negatively impact our brain tasks. In addition, the results suggest that iPhone can be an extension of ourselves, and we will experience a diminished and negative physiological state when separated [10]. At the same time, with the application of mobile phones, people are more fond of online shopping because of its convenience, which stimulates consumers' impulse consumption more. In Malin Sundstorm's research, young consumers buying fashion items online are often motivated by boredom. When consumers are bored, they are easily motivated to buy by various activities such as discounts, cash back, and free shipping fees [11].

Fast moving consumer goods(FMCG). Fast moving consumer goods are those products with short life cycle and easy to be reused. Research by Uzma Hasan and Dr. Reshma Nasreen unveils that "consumers may face more inconsistencies in their decision to buy luxury goods and less inconsistencies in their decision to buy FMCG goods." [12] Nowadays many commodities in life, especially drinks such as milk tea, are paid by teenagers unconsciously. The price paid each time is low, but frequency is high, resulting in excessive consumption.

Advertising. With the development of the Internet, people are always faced with a variety of advertising, while teenagers, because they do not have enough experience and cognition, cannot resist the temptation in the face of publicity. Tirtha Dhar and Kathy Baylis used survey data on household expenditure for the Canadian population affected by the ban from 1984 to 1992 and found that banning advertising reduced people's propensity to buy [13].

Online lending has become more convenient. Research on China's Consumer Credit Market 2018 released by Tsinghua University in January 2019 shows that customers of consumer credit tend to be young, with 18 to 29 years old students and fresh graduates accounting for the highest proportion, becoming the main body of Consumer credit in China. However, most of them have a monthly income of less than 5,000 yuan.

\subsection{Advice on Rational Consumption}

It's impossible for everyone to consume completely rationally in their lives, and there will be several advises to help reduce this situation. 
Before purchasing, people can make a list, then strictly follow it when shopping in offline shopping malls or online platforms, and try not to be attracted by the posters in shopping malls and make temporary purchases. A spending list can be implemented by sticking with it for a while and then lasting longer. But the most important thing is to strengthen self-control, and learn to delay and moderate consumption. Jevons first claimed that when people make inter-temporal trade-off, they may control their current behaviors in order to predict the utility of their behaviors in the future, so as to get better returns in the future [14]. Also, he proved the theory by applying the Benthamite concept of utility. In view of the problem of limited willpower, young people can grow self-control ability, such as before buying behavior, thinking how much satisfaction there will be after the purchase [15], or put the goods in the shopping cart, making decisions on purchase in a few days. These measures could help themselves to reduce excessive or useless consumption behaviors through procrastination, and remind them whether the money will bring better returns if used in other places. Also, teenagers should learn to prevent consumption addiction. Young people should actively face and avoid consumption addiction after clearly discovering it. For example, taking more social activities and expanding hobbies and interests to shift their attention away from shopping.

\subsection{Impacts on the People}

The environment of excessive consumption will further distort young people's values, making them completely immersed in reckless consumption, and unable to extricate themselves, which will fundamentally destroy and corrode young people's ambition and morale.

Meanwhile, most teenagers have no income that corresponds to expenditure, which means that they have been using their parents' money, leading to the increase of burden on the family. In fact, some people take out loans to cover their expenses, but they cannot pay them back. They might continue to take out loans to repay. Finally, they owe more money. This intensifies the conflict in the family. Similarly, because of the addictive nature of excessive consumption, the satisfaction of a desire is followed by a greater desire, but after satisfying all of them, there will just be a feeling of emptiness left. In addition, under such temptation, some teenagers will go to extremes, causing harm to the society.

\section{CONCLUSION}

Nowadays excessive and impulsive consumption are common problems among young people. They are usually caused and promoted by cognitive biases in the heart, as well as the popularity and publicity of mobile phones and advertisements in the society. However, teenagers do not have enough experience to distinguish and resist them. To a certain extent, excessive consumption can drive economic growth. However, when severe overconsumption occurs, it imposes a great burden on themselves and their families. What people need to do most is to reduce their consumption by strengthening their self-control, aided by procrastination, lists, etc. However, there are more internal and external factors connected to excessive consumption and impulse consumption, which requires more surveys and experiments to confirm it. When the relationships get clearer, it could be more effective to prevent excessive and impulse buying.

\section{ACKNOWLEDGMENT}

First of all, I would like to show my gratitude to my teacher in my high school, professor, and teaching assistant in the project, who instructed me how to write a paper and help me whenever I have problems. Meanwhile, I want to thank my classmates and friends, who encourage me when I frustrated with a problem. I cannot complete this paper without all their guidance and encouragement.

\section{REFERENCES}

[1] Electronic commerce data center http://www.mofcom.gov.cn/article/ae/ah/diaocd/201811/201811028 07185.shtml, (2018).

[2] G. Katona, Rational behavior and economic behavior. Psychological review, (1953) 60(5), 307.

[3] G. S. Becker, Irrational behavior and economic theory. Journal of political economy, (1962) 70(1), $1-13$.

[4] W. James, The perception of reality. Principles of psychology, (1890) 2, 283-324.

[5] M. J. Sirgy, Self-concept in consumer behavior: A critical review. Journal of consumer research, (1982) 9(3), 287-300.

[6] G. S. Becker, \& K. M. Murphy, A theory of rational addiction. Journal of political Economy,(1988) 96(4), 675-700.

[7] S. Lichtenstein, B. Fischhoff, \& L. D. Phillips, Calibration of probabilities: The state of the art to 1980 (No. PTR-1092-81-6). DECISION RESEARCH EUGENE OR. 1981.

[8] J. Schor, The Overspent American. HarperCollins Publisher, Newton, 1999.

[9] Z. Ian, What Motivated Impulse buying?. Psychology Today. (2012, 01) https://www.psychologytoday.com/us/blog/sold/20 1207/what-motivates-impulse-buying 
[10] News Bureau, University of Missouri. iPhone Separation Linked to Physiological Anxiety, Poor Cognitive Performance, MU Study Finds (2015) https://munewsarchives.missouri.edu/newsreleases/2015/0108-iphone-separation-linked-tophysiological-anxiety-poor-cognitive-performancemu-study-finds/

[11] M., Sundström, S. Hjelm-Lidholm, \&A. Radon, Clicking the boredom away-Exploring impulse fashion buying behavior online. Journal of Retailing and Consumer Services, (2019) 47, 150-156.

[12] U. Hasan, \& R. Nasreen, Cognitive dissonance and its impact on consumer buying behaviour. IOSR J Bus Manag, (2012) 1, 7-12.

[13] T. Dhar, \& K. Baylis, Fast-food consumption and the ban on advertising targeting children: the Quebec experience. Journal of Marketing Research, (2011) 48(5), 799-813.

[14] W. S. Jevons, The Principles of Economics. Henry Holt and Company. New York, 1905.

[15] W. Al-Shahib, \& R. J.Marshall, The fruit of the date palm: its possible use as the best food for the future? International journal of food sciences and nutrition, (2003) 54(4), 247-259. 